\title{
USP Disintegration Apparatus as a Potential Tool for Evaluating Drug Release from Controlled-Release Dosage Forms
}

\author{
Monica C. Chuong' ${ }^{1}$, Ronald G. Lee, Vaibhav Saxena, and \\ Luca Palugan \\ Department of Pharmaceutical Sciences, School of Pharmacy, Massachusetts College of \\ Pharmacy and Health Sciences - Boston, 179 Longwood Ave., Boston, MA 02115
}

\begin{abstract}
Official compendia lack in vitro dissolution guidelines for simulated fed conditions. The goal of this project was to compare disintegration times and drug release characteristics for Polygel CR tablets using USP dissolution Apparatus 1 and the USP disintegration apparatus. Calcium tablets plus vitamin D with different deaggregation properties were also used to study the food-weight effect on tablet disintegration. A USP disk, either flat or on its side, was placed on a tablet contained inside the USP disintegration apparatus to simulate the dosage form being in total contact with food after a heavy meal or in partial contact with food after a light meal, respectively. Drug release profiles for Polygel CR tablets in a simulated fasted state were not remarkably different whether the USP disintegration apparatus or USP dissolution Apparatus 1 was used $(66.3 \pm 2.1 \%$ versus $55.3 \pm 1.3 \%$ in $6 \mathrm{~h})$. Drug release, however, was observed to be higher in the simulated fed state when the USP disintegration apparatus with a disk was used $(88.9 \pm 5.9 \%$ versus $47.5 \pm 0.8 \%$ in $6 \mathrm{~h}$, $p<0.05)$. The data generated using calcium tablets plus vitamin $\mathrm{D}$ also suggest that food weight does not significantly accelerate the disintegration of tablets designed with rapid disintegration properties. However, the presence of a meal in the stomach may speed up the disintegration of slower disintegrating tablets.
\end{abstract}

\section{INTRODUCTION}

n 1968 Pernarowski et al. (1) developed the rotating basket dissolution apparatus, and shortly after that, Poole (2) invented the paddle dissolution method. These two designs have become USP Apparatus 1 and Apparatus 2, respectively, and are still the most commonly used instruments. In 1970 the first official dissolution test for a solid dosage form was published in USP XVIII (3). Since then, dissolution has become widely accepted as a useful tool to reduce development costs, a means to screen formulations, and a way to prepare the conduct of clinical trials and reduce their costs. The FDA has also considered dissolution as a test for the quality control of drug products that is separate and distinct from disintegration (4). In addition, dissolution testing provides information about how excipients chosen during research and development impact the dissolution profiles. Substantial debate on the use of dissolution as a quality control test has taken place, including arguments that a drug product could fail the dissolution test without showing an effect on bioavailability or efficacy (3). One of the reasons for this is that most dissolution scientists work in as simplified a fashion as possible; thus, what happens in a dissolution vessel is not a simulation of what happens in the body. The food-weight effect on a solid dosage form

${ }^{1}$ Corresponding author. has not been investigated thoroughly in vitro. There is also lack of compendial guidelines.

To propose a new in vitro model for studying drug release from controlled-release (CR) tablets in both fasted and fed conditions, three different brands of over-thecounter calcium tablets and a Polygel CR niacin tablet were chosen as the model dosage forms for this project. Niacin $\left(\mathrm{C}_{6} \mathrm{H}_{5} \mathrm{NO}_{2}\right)$, which has a molecular weight of 123.11 $\mathrm{g} / \mathrm{mol}$, a solubility of $16.67 \mathrm{mg} / \mathrm{mL}(5)$, and a $\mathrm{pK}_{\mathrm{a}}$ of $2.2(6)$, is known as nicotinic acid or vitamin $B_{3}$. It is one of the essential components of the normal human diet and is important for metabolism. Advanced deficiency of niacin can lead to a condition called pellagra, in which individuals develop diarrhea, dermatitis, and dementia (5). Niacin is also used therapeutically to reduce cholesterol and triglyceride levels in the blood. Specifically, it reduces low density lipoprotein and increases high density lipoprotein. Therefore, the main medicinal use of niacin in the United States today is for its hypolipidemic response by lowering serum cholesterol by $10-15 \%$ and triglycerides by $20-30 \%$ (7).

The role of calcium in bone health is indisputable. Calcium is absorbed in the small intestine. The amount of calcium absorbed depends on a several factors such as the acidic condition in the intestines, vitamin D level, estrogen level, and the type of calcium supplement. The elemental calcium content is what is important to the consumer. For instance, a tablet containing $500 \mathrm{mg}$ of calcium carbonate 
has $200 \mathrm{mg}$ of elemental calcium. Hence, one tablet in this example only provides $200 \mathrm{mg}$ of calcium, not $500 \mathrm{mg}$ (8).

The current dissolution method listed in USP 31/NF 26 for niacin tablets (9) suggests using $900 \mathrm{~mL}$ of $0.1 \mathrm{~N} \mathrm{HCl}$ with the USP Apparatus 1 (basket) method; the tolerance is not less than $65 \%$ of the labeled amount of niacin dissolved in $60 \mathrm{~min}$. These guidelines are not for niacin CR tablets. Since drug release from such formulations in the human gastrointestinal tract (GIT) involves passing through media of different $\mathrm{pH}$ levels, a dissolution method should include media changes from one stage to another.

Therefore, the overall purpose of this project was three-fold. First, it was to investigate how the media should be prepared and changed when the dissolution study was advanced from acid stage to buffer stage. Two medium change methods are available in the USP (10): add directly, and drain and add (8). However, the current method is written for an immediate-release dosage form and gives no instructions as to which method should be used for extended-release niacin tablets. The question is, Are both medium change methods applicable to the assessment of hydrogel dosage forms, or is one method superior to the other?

The second aim was to compare drug release from the Polygel model dosage form in both simulated fasted and simulated fed conditions by using USP dissolution Apparatus 1 and the USP disintegration apparatus. A USP disk (11) weighing $3.05 \mathrm{~g}$ would be placed on top of the tablet to simulate food-weight effect on drug release. To accomplish this, the dissolution media were prepared based on the physiological $\mathrm{pH}$ of a human stomach and small intestine when food was present or not, and the dissolution experimental time was made comparable to the retention time of each section in the GIT (Table 1).

The last purpose was to propose a model that allows the study of food weight effect upon a tablet by placing a USP disk on a tablet in different positions. The use of a disk laid flat simulated a tablet that was in total contact with food after a heavy meal, whereas a disk lying sideways simulates a tablet in partial contact with food after a light meal. Calcium tablets plus vitamin D from three different manufacturers were used to test this particular model.

\section{MATERIALS AND METHODS \\ Materials \\ Reagents and standards}

Niacin reference standard (Niacin RS, Supelco, MO), hydrochloric acid (36.5-38\%), sodium hydroxide pellets, and HPLC grade acetonitrile were purchased from VWR International (Bridgeport, NJ). Tribasic sodium phosphate was obtained from PCCA (Houston, TX).

\section{Dissolution Media}

Three media, $0.1 \mathrm{~N} \mathrm{HCl}, \mathrm{pH} 2.2$ hydrochloric acid buffer, and $\mathrm{pH} 6.8$ phosphate buffer, were prepared according to the guidelines listed in the USP (15). Hydrochloric acid $(0.1 \mathrm{~N})$ was used as simulated fasted gastric fluid, $\mathrm{pH} 2.2$ $\mathrm{HCl}$ buffer as simulated fed gastric medium, and $\mathrm{pH} 6.8$ phosphate buffer as simulated small intestinal fluid in both fasted and fed states.

\section{Instrumentation}

A Hewlett Packard Model 8453 UV-vis spectrophotometer (New Brunswick, NJ) was used to analyze dissolution and disintegration samples. Dissolution studies were performed with a Distek Premier 5100 seven-vessel system. The USP disintegration apparatus consisted of a basket-rack assembly and a $1000-\mathrm{mL}$ beaker with immersion fluid maintained at $39 \pm 1^{\circ} \mathrm{C}$ by a water bath (Precision Scientific, Model 183, Chicago, IL) to simulate body core temperature.

\section{Commercial Tablet Model Dosage Forms \\ Polygel CR tablet}

SloNiacin, an over-the-counter 500-mg Polygel

CR tablet (Upsher-Smith Laboratories Inc., MN), was obtained from a local pharmacy. The excipients listed in

Table 1. Comparison of Different Parts of the Gastrointestinal Tract ${ }^{a}$

\begin{tabular}{|c|c|c|c|c|c|c|c|}
\hline & \multicolumn{2}{|c|}{ Fasted State } & \multicolumn{2}{|c|}{ Fed State } & \multicolumn{3}{|c|}{ Ionic Concentration (nM) } \\
\hline & pH & Residence Time & pH & Residence Time & $\mathrm{Na}^{+}$ & $\mathrm{HCO}_{3}^{-}$ & $\mathrm{Cl}^{-}$ \\
\hline Esophagus & 6.8 & $>30 \mathrm{sec}$ & & & & & \\
\hline Stomach & $1-2$ & $1-5 \mathrm{~h}$ & $2-5^{*}$ & * & 70 & $<20$ & 100 \\
\hline Duodenum & $6.1(5-6.5)$ & $>5 \mathrm{~min}$ & $4.5-5.5(1 \mathrm{~h})$ & $1 \mathrm{~h}$ & & & \\
\hline Jejunum & $6.5(6.0-7.0)$ & $1-2 \mathrm{~h}$ & 4.7 (2 h) & $2 \mathrm{~h}$ & 140 & $50-110$ & 130 \\
\hline Ileum & 6.5 & $2-3 h$ & 6.5 & * & & & \\
\hline Colon & $5.5-7.8$ & $15-48 h$ & 8.0 & up to $72 \mathrm{~h}$ & & & \\
\hline
\end{tabular}

${ }^{a}$ Combined from ref $12-14$

*Dependent on volume, $\mathrm{pH}$, and buffer capacity of the food. 
the Polygel CR product label were glycerol behenate, hydrogenated vegetable oil, hypromellose (hydroxypropyl methylcellulose), magnesium stearate, silicon dioxide, and Red 40 (5).

\section{Calcium plus vitamin $D$ tablets}

Three different brands of 500-mg calcium tablets with vitamin D (Nature Made, CVS, and OsCal) were purchased from a local pharmacy. The ingredients of these commercial calcium tablet products are listed in Table 2.

Table 2. Excipients of Three Brands of 500-mg Calcium Tablets with Vitamin D

\begin{tabular}{|c|c|c|c|}
\hline Excipient & Nature Made & CVS & OsCal \\
\hline Acacia Gum & & $\sqrt{ }$ & \\
\hline Calcium Carbonate & $\sqrt{ }$ & & $\sqrt{ }$ \\
\hline Calcium Stearate & & & $\sqrt{ }$ \\
\hline Carnauba Wax & $\sqrt{ }$ & & \\
\hline Cellulose Coating & & $\sqrt{ }$ & \\
\hline Cholecalciferol & & & $\sqrt{ }$ \\
\hline Corn Starch & & & $\sqrt{ }$ \\
\hline Corn Syrup Solids & & & $\sqrt{ }$ \\
\hline Croscarmellose & & $\sqrt{ }$ & \\
\hline Gelatin & & & $\sqrt{ }$ \\
\hline Glycerin & $\sqrt{ }$ & & \\
\hline $\begin{array}{l}\text { Hydroxypropyl } \\
\text { Methylcellulose }\end{array}$ & $\sqrt{ }$ & & \\
\hline Magnesium Stearate & & $\sqrt{ }$ & \\
\hline Maltodextrin & $\sqrt{ }$ & $\sqrt{ }$ & \\
\hline Methylparaben & & & $\sqrt{ }$ \\
\hline Mineral Oil & $\sqrt{ }$ & & \\
\hline Vegetable Oil & & $\sqrt{ }$ & \\
\hline Polyethylene Glycol & $\sqrt{ }$ & & $\sqrt{ }$ \\
\hline Polysorbate 80 & & & $\sqrt{ }$ \\
\hline Polyvinyl Alcohol & & & $\sqrt{ }$ \\
\hline Propylparaben & & & $\sqrt{ }$ \\
\hline Sodium Starch Glycolate & & & $\sqrt{ }$ \\
\hline Sucrose & & & $\sqrt{ }$ \\
\hline Talc & & & $\sqrt{ }$ \\
\hline Titanium Dioxide & & $\sqrt{ }$ & $\sqrt{ }$ \\
\hline dl-alfa Tocopherol & & & $\sqrt{ }$ \\
\hline
\end{tabular}

Methods

\section{Construction of Niacin Standard Curves}

The absorbance maxima of niacin in $0.1 \mathrm{~N} \mathrm{HCl}, \mathrm{pH} 2.2$ hydrochloric acid buffer, and $\mathrm{pH} 6.8$ phosphate buffer were determined to be $261 \mathrm{~nm}, 261 \mathrm{~nm}$, and $263 \mathrm{~nm}$, respectively. One hundred milligrams of Niacin RS was dissolved in $100 \mathrm{~mL}$ of $0.1 \mathrm{~N} \mathrm{HCl}, \mathrm{pH} 2.2 \mathrm{HCl}$ buffer, and $\mathrm{pH}$ 6.8 phosphate buffer to prepare stock solutions. To construct standard curves, the stock solutions were diluted to concentrations of $0.01,0.02,0.04,0.1,0.3$, and $0.4 \mathrm{mg} / \mathrm{mL}$ for $0.1 \mathrm{~N} \mathrm{HCl}$ and $\mathrm{pH} 2.2 \mathrm{HCl}$ buffer, and 0.0016 , $0.008,0.04,0.2$, and $1 \mathrm{mg} / \mathrm{mL}$ for the $\mathrm{pH} 6.8$ phosphate buffer. The lower concentration was included for the $\mathrm{pH}$ 6.8 phosphate buffer standard curve because release of niacin Polygel was lower in this $\mathrm{pH}$. Standard curves for niacin in $0.1 \mathrm{~N} \mathrm{HCl}, \mathrm{pH} 2.2 \mathrm{HCl}$ buffer, and $\mathrm{pH} 6.8$ phosphate buffer had correlation coefficients $\left(r^{2}\right)$ of $0.9998,0.9993$, and 0.9995 , respectively. The linear range for niacin in $0.1 \mathrm{~N} \mathrm{HCl}$ and $\mathrm{pH} 2.2 \mathrm{HCl}$ buffer was 0.01 to $0.40 \mathrm{mg} / \mathrm{mL}$, and in $\mathrm{pH} 6.8$ phosphate buffer, 0.0016 to $1.00 \mathrm{mg} / \mathrm{mL}$.

\section{Investigation of Dissolution Medium-Change Methods Method A: Add Directly}

A Polygel CR tablet was placed in Apparatus 1 with $500 \mathrm{~mL}$ of deaerated $0.1 \mathrm{~N} \mathrm{HCl}$ at $50 \mathrm{rpm}$. After two hours, $500 \mathrm{~mL}$ of deaerated $0.0375 \mathrm{M}$ tribasic sodium phosphate $\left(\mathrm{Na}_{3} \mathrm{PO}_{4}\right)$ preheated to $37 \pm 0.5^{\circ} \mathrm{C}$ was added. The deaeration was done by filtering the medium through a $0.25-\mu \mathrm{m}$ porosity, $2.5-\mathrm{cm}$ diameter PTFE membrane assembled in a suction flask. The resulting buffer solution was adjusted to $\mathrm{pH} 6.8$ by addition of $2 \mathrm{~N} \mathrm{NaOH}$ to mimic small intestinal fluid.

\section{Method B: Drain and Add}

For method $B$, the initial dissolution operating conditions were the same as for method $A$. At the end of two hours, the dissolution platform was lifted into the air for $10 \mathrm{~min}$. The medium was drained from the dissolution vessel, then $1000 \mathrm{~mL}$ of preheated, deaerated pH 6.8 phosphate buffer was added. The platform was then lowered and stirring was resumed at $50 \mathrm{rpm}$ for four hours. The sampling time points during the acid stage were $0.25,0.5,1,1.5$, and $2 \mathrm{~h}$; those for the buffer stage were $0.25,0.5,1,1.5,2$, and $4 \mathrm{~h}$. The acid samples were quantified spectrophotometrically at $261 \mathrm{~nm}$, and the phosphate buffer samples at $263 \mathrm{~nm}$.

\section{Drug Release from Polygel Formulation during Fasted and Fed State}

The same media were prepared for both the dissolution and disintegration experiments. In the simulated fasted condition, a Polygel CR tablet was immersed in $0.1 \mathrm{~N} \mathrm{HCl}$ for $2 \mathrm{~h}$ and then in $\mathrm{pH} 6.8$ phosphate buffer for $4 \mathrm{~h}$.

\section{Disintegration study}

The test apparatus was calibrated to ensure that the USP standard (11) had been met; that is, the basket was 
raised and lowered in $800 \mathrm{~mL}$ of deionized water as the immersion fluid at 29-32 cycles per minute. The volume of fluid in the vessel was such that at the highest point of the upward stroke, the wire mesh remained at least $2.5 \mathrm{~cm}$ below the surface of the fluid and descended to not less than $2.5 \mathrm{~cm}$ from the bottom of the vessel on the downward stroke. Then $800 \mathrm{~mL}$ of preheated $\left(39 \pm 1{ }^{\circ} \mathrm{C}\right)$ deaerated $0.1 \mathrm{~N} \mathrm{HCl}$ was used as the test immersion fluid to mimic a tablet in an empty stomach. At the end of two hours, the apparatus was paused. The basket containing the Polygel tablet was quickly switched to another beaker containing $800 \mathrm{~mL}$ of deaerated $\mathrm{pH} 6.8$ phosphate buffer preheated to $39^{\circ} \mathrm{C}$ to mimic the intestinal fluid. No disk was applied to a test tablet. Operation of the apparatus was resumed for four hours. Six milliliters of immersion fluid was collected with replenishment of an equal volume of fresh medium during each sampling point. The sampling schedule at the acid stage was 0.25 , $0.5,1,1.5$, and $2 \mathrm{~h}$, and that of buffer stage was $0.25,0.5,1$, 2,3 , and $4 \mathrm{~h}$. Acidic samples were assayed spectrophotometrically at $261 \mathrm{~nm}$, and buffer stage samples at $263 \mathrm{~nm}$. A correction factor for these sampling volumes was implemented during data analysis. When the concentration of an undiluted sample was suspected to be outside the linear range of the standard curve, the sample solution was further diluted two-fold before assay.

\section{Dissolution study}

USP Apparatus $1(10,16,17)$ was chosen for the dissolution study with $500 \mathrm{~mL}$ of preheated $\left(39 \pm 1^{\circ} \mathrm{C}\right)$ deaerated $0.1 \mathrm{~N} \mathrm{HCl}$. The basket rotation speed was set at $50 \mathrm{rpm}$ for $2 \mathrm{~h}$ to simulate the fasted gastric condition. Then medium change Method A, Add Directly, was used to bring the medium to $1000 \mathrm{~mL}$ at $\mathrm{pH}$ 6.8. The dissolution study continued at $50 \mathrm{rpm}$ for another $4 \mathrm{~h}$ to simulate the fasted condition in the small intestine. The sampling schedule and assay method were the same as those for the disintegration study.

\section{Drug Release from Polygel Formulation during Fed State}

In the simulated fed study, a tablet was studied in $\mathrm{pH} 2.2 \mathrm{HCl}$ buffer for $6 \mathrm{~h}$ in both dissolution and disintegration studies.

\section{Disintegration study}

The apparatus conditions were the same as described above with two exceptions; $\mathrm{pH} 2.2 \mathrm{HCl}$ buffer was used, and a USP disk weighing $3.05 \mathrm{~g}$ was placed flat on the top of the tested tablet to mimic the effect of food weight in maximal contact with the test tablet after a heavy meal. Samples were collected at $0.25,0.5,1,1.5,2,3,4$, and $6 \mathrm{~h}$ and quantified spectrophotometrically at $261 \mathrm{~nm}$.

\section{Dissolution study}

Apparatus 1 was chosen for the dissolution study with $1000 \mathrm{~mL}$ of preheated $\mathrm{pH} 2.2$ phosphate buffer and a basket rotation speed of $100 \mathrm{rpm}$ for $6 \mathrm{~h}$ to simulate fed condition. Sampling schedule was the same as that for the disintegration study above.

\section{Evaluation of Effect of Disk Position on the Disintegration Time of Calcium Tablets}

Hardness testing (Schleuniger-2E, Vicotr Co., Marion, IA) of all three brands of calcium with vitamin $D$ tablets (Nature Made, CVS, and OsCal) was performed to eliminate the concern of a formulation parameter that may bias the disintegration results. All brands had hardness greater than 20 kiloponds.

A USP disk was placed in different positions on a calcium tablet inside the tube of the disintegration basket to simulate light or heavy food weight. Disk laid flat was to mimic the tablet being compacted by a full meal, while disk laid upright with its side in contact with the test tablet was to simulate a calcium tablet being partially touched by a light meal in the stomach. The time when a calcium tablet was completely disintegrated inside the apparatus was then recorded.

\section{Statistical Analysis}

Excel 2000 (Microsoft) was used to manage raw data. Using SigmaStat 3.5 (SYSTAT Software Inc., San Jose, CA), independent $t$-test and one-way ANOVA were performed for two-group data and three-group data analysis when normality and equal variance met. All pairwise multiple comparison procedure (Tukey Test) was selected as the posthoc test (18). Rank Sum test and Kruskal-Wallis ANOVA on Ranks were chosen for two-group and three-group comparisons when unequal variance existed. Population differences are considered significant at $p<0.05$ (18).

\section{RESULTS}

\section{Medium Change Methods}

The niacin released from the Polygel CR tablet in acid stage during simulated fasted condition was biphasic: curved in the acid stage (Figure 1A) and linear in the buffer stage (Figure 1B). The best-fit equation obtained for the release versus time profile in the acid stage is:

$$
Y=19.482 X^{3}-88.033 X^{2}+183.06 X+1.624
$$

where $X$ is time in $\mathrm{hr}$ and $Y$ is the amount of niacin (mg) released into the medium. The correlation coefficient, $r^{2}$, is 0.9988.

When Method A (Add Directly) was used to change dissolution medium from acidic $\mathrm{pH}$ to $\mathrm{pH} 6.8$, the 4-hr drug release from a Polygel CR tablet was linear, and the release rate during this buffer stage was $27.5 \pm 1.5 \mathrm{mg} / \mathrm{h}$. But when Method B (Drain and Add) was used to change medium, the release rate was significantly slowed. The computed average of the release rate was only $16.5 \pm 5.8$ $\mathrm{mg} / \mathrm{h}(n=8, p<0.001$, Table 3$)$. 
(A)

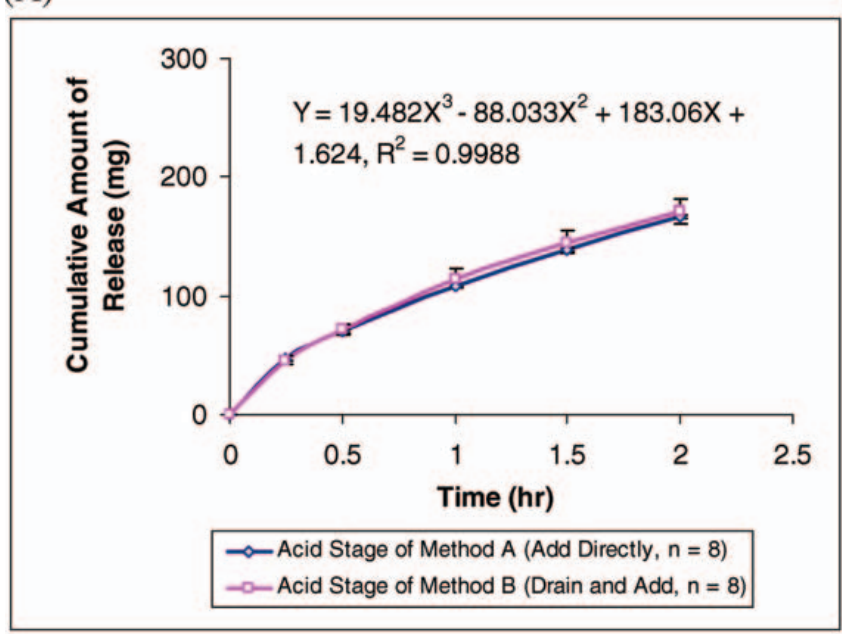

(B)

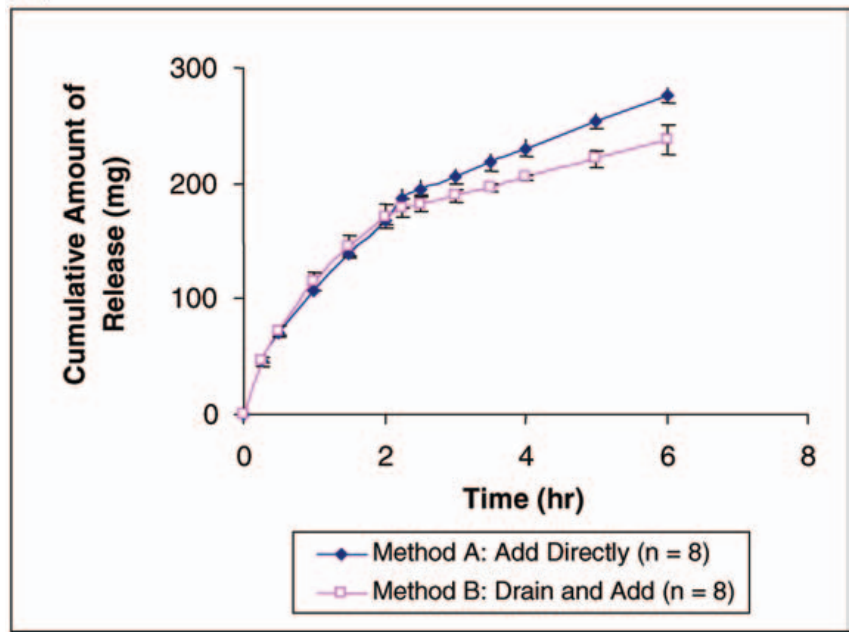

Figure 1. Niacin release from a Polygel CR tablet using Method A vs. Method $B$ to change medium. Release in acid stage during simulated fasted condition was biphasic: $(A)$ curved in the acid stage and (B) linear in the buffer stage.

\section{Drug Release from the Polygel Formulation during Fasted and Fed States}

Use of a disintegration apparatus or a dissolution apparatus did not seem to affect the cumulative percent niacin release from a Polygel CR tablet during simulated fasted condition at the end of 6-h experimental period $(66.3 \pm 2.1 \%, n=6$ versus $55.3 \pm 1.3 \%, n=8$, Table 4$)$. The cumulative percent of drug release in $6 \mathrm{~h}$, however, was much higher in the simulated fed state when the USP disintegration apparatus with a disk of $3.05 \mathrm{~g}$ was applied to simulate the food-weight effect (Figure 2). The results were $88.9 \pm 5.9 \%, n=6$ versus $47.5 \pm 0.8 \%, n=5$ (Table 4).

The cumulative percent of niacin release from a Polygel CR tablet in simulated fasted and simulated fed states were plotted for USP dissolution Apparatus 1 and the USP disintegration apparatus. The correlation coefficient, $r^{2}$,
Table 3. Comparison of Medium Change Methods on Niacin Release Rates from Polygel CR Tablet during 4-h Buffer Stage (pH 6.8) Dissolution Study

\begin{tabular}{lcc}
\hline \multicolumn{3}{c}{ Release Rate } \\
\cline { 2 - 3 } Sample ID & Method A $(\mathrm{mg} / \mathrm{h})$ & Method B $(\mathrm{mg} / \mathrm{h})$ \\
\hline 1 & 25.21 & 11.04 \\
\hline 3 & 26.52 & 11.29 \\
\hline 4 & 25.86 & 11.44 \\
\hline 5 & 26.99 & 11.04 \\
\hline 6 & 29.20 & 22.95 \\
\hline 7 & 28.74 & 20.25 \\
\hline 8 & 28.45 & 22.88 \\
\hline Avg \pm SD & 28.81 & 21.49 \\
\hline
\end{tabular}

${ }^{a} p<0.001$

Table 4. Percentage Niacin Released from a Polygel CR Tablet in 6 h Using USP Apparatus 1 and Disintegration Apparatus

\begin{tabular}{lcc}
\hline & Disintegration Apparatus & Dissolution Apparatus 1 \\
\hline Fasted & $66.3 \pm 2.1 \%(n=6)$ & $55.3 \pm 1.3 \%(n=8)$ \\
\hline Fed & $88.9 \pm 5.9 \%(n=6)$ & $47.5 \pm 0.8 \%(n=5)$ \\
\hline
\end{tabular}

was 0.9976 for simulated fasted state, which was $0.1 \mathrm{~N} \mathrm{HCl}$ as test medium for $2 \mathrm{~h}$, then $\mathrm{pH} 6.8$ phosphate buffer for $4 \mathrm{~h}$. No disk was added to the USP disintegration apparatus, and the basket spinning rate of the USP dissolution apparatus was $50 \mathrm{rpm}$. The $r^{2}$ value was 0.9955 for the simulated fed study (Figure 3 ). In this case, $\mathrm{pH} 2.2 \mathrm{HCl}$ buffer was used as the test medium. A 3.05-g disk was added on top of the test tablet inside the disintegration apparatus. The basket rotation speed was $100 \mathrm{rpm}$. The $r^{2}$ values were similar, but the slope of the simulated fed state trend line was 1.7 times that of the simulated fasted state trend line (1.933 versus 1.143, Figure 3 ).

\section{Calcium Tablet Disintegration Time with a USP Disk at Different Positions inside the Apparatus}

Among the three brands of 500-mg calcium with vitamin D tablets tested with and without a USP disk and in different disk positions (laid flat vs. laid upright) to mimic different degrees of food weight effect on a tablet disintegration, neither the presence of a disk nor the position of a disk made a difference in the disintegration of the CVS and OsCal brands. Nature Made calcium and vitamin $\mathrm{D}$ tablets disintegrated faster with a disk laid flat on top than with a disk laid upright $(9.88 \pm 0.68$ min versus 
(A)

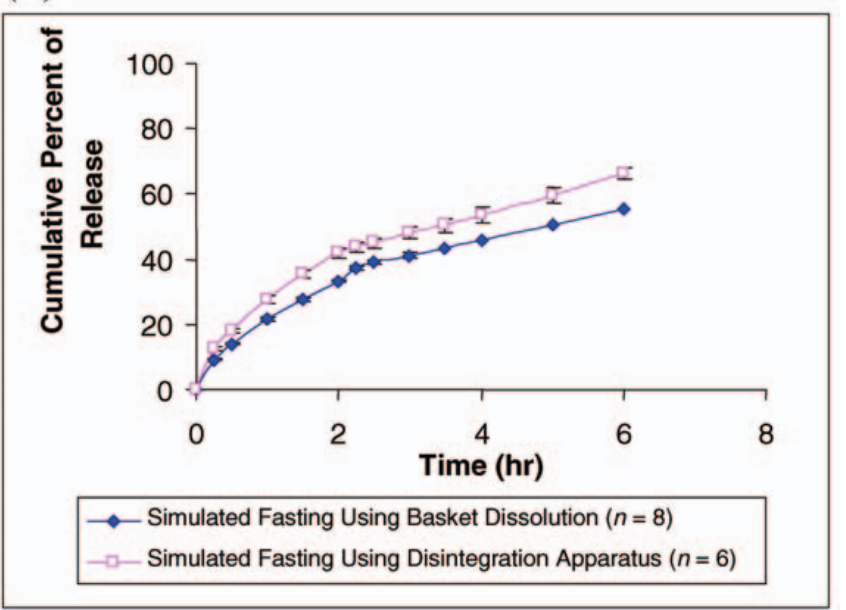

(B)

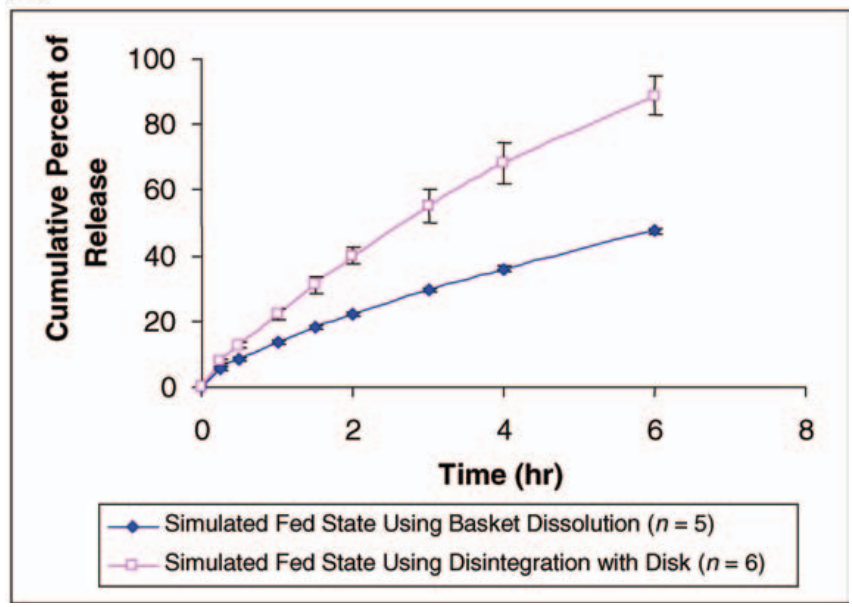

Figure 2. Niacin release from a Polygel CR tablet in $(A)$ fasted and $(B)$ fed conditions using USP dissolution Apparatus 1 and the USP disintegration apparatus.

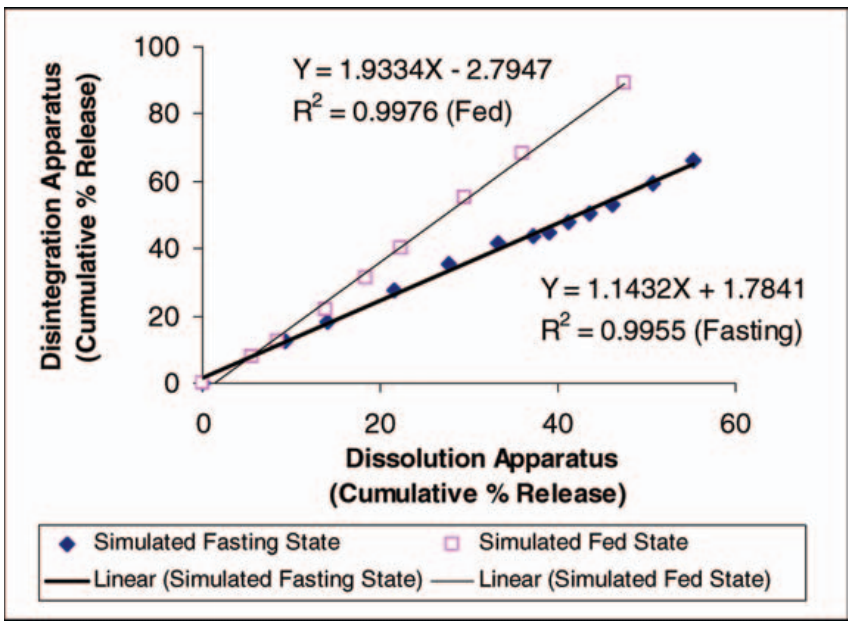

Figure 3. Comparison of correlation of niacin release from a Polygel CR tablet using USP dissolution Apparatus 1 and the USP disintegration apparatus for simulated fasted state (no disk added) and simulated fed states (disk on top of the test tablet).
14.7 $\pm 1.30 \min , n=9, p<0.05$, Table 5). The disintegration of Nature Made calcium and vitamin D tablets was slowest when no disk was applied (20.43 $\pm 0.93 \mathrm{~min}, n=9$, Table 5).

\section{DISCUSSION}

Method A (Add Directly) was superior to Method B (Drain and Add) during the dissolution test of a Polygel $\mathrm{CR}$ tablet for the following three reasons. First, after tablet exposure to an acidic medium for $2 \mathrm{~h}$, the swollen scaffold of the Polygel tablet may deswell due to the lack of medium support when the dissolution platform is lifted to change dissolution medium as required in Method B. The air may also block the channels and affect the diffusion of drug molecules after the platform is returned to the system (Figure 4). Second, Method A simulates the physiological environment more closely as it is a continuous process for a tablet to travel in the medium from the stomach into the small intestine (Table 1). Third, data indicate that the errors between vessels and between run variations are smaller when Method $A$ is employed (Figure 3B). Hence, Method A is recommended for the dissolution study of a Polygel CR tablet.

The niacin released from the Polygel CR tablet, a hydrogel and lipophilc matrix system, in acid stage during simulated fasted dissolution study was observed as biphasic: curved in the acid stage and linear in the buffer stage (Figure 1). The excipients controlling the niacin release from the Polygel CR product (e.g., glycerol behenate, hypromellose) are $\mathrm{pH}$-independent. In the beginning of the dissolution study, which was in the acidic medium, the niacin molecules present on and near the surface of the tablets dissolved quickly. As time progressed, the release rate slowed due to the increased diffusion distance, which may explain why the release in acidic medium is a curve. But during the $\mathrm{pH} 6.8$ phosphate buffer stage, the release profile became linear instead of moving upward as a curve (data not shown). Although the reason is unknown, we speculate that this observation may be linked to the charge interactions among niacin ions, hydrogen ions, chloride ions, sodium ions, and mono- and bi-basic phosphate ions present in the medium, making the release rate of niacin from the inner part of the tablet through gel material more constant (Figure 1, Table 3).

The correlation coefficients, $r^{2}$, using USP dissolution Apparatus 1 and the USP disintegration apparatus for niacin release from a Polygel CR tablet in simulated fasted state (no disk added) and simulated fed states (with a disk of $3.05 \mathrm{~g}$ on top of test tablet) were 0.9976 and 0.9955 , respectively, implying that both apparatus performed precisely and reliably within the test period (6 h) under the proposed experimental conditions. But the slope of simulated fed state trend line was 1.7 times that of the simulated fasted state trend line ( 1.933 versus 1.143). This observation suggests that using a USP 
Table 5. Disintegration Times of Three Brands of Calcium Tablets with and without a USP Disk

\begin{tabular}{llll}
\hline Disk Configuration & OsCal $(\min )$ & CVS $(\min )$ & Nature Made $($ min) \\
\hline No Disk $^{a}$ & $9.23 \pm 2.73(n=16)$ & $3.71 \pm 0.25(n=5)$ & $20.43 \pm 0.93(n=9)$ \\
\hline Disk Laid Flat $^{b}$ & $7.26 \pm 0.93(n=16)$ & $2.86 \pm 0.12(n=5)$ & $9.88 \pm 0.68^{d}(n=9)$ \\
\hline Disk Laid Upright $^{c}$ & $7.84 \pm 1.10(n=16)$ & $3.10 \pm 0.25(n=5)$ & $14.79 \pm 1.30^{d}(n=9)$ \\
\hline
\end{tabular}

${ }^{a}$ Represents fasted state.

${ }^{\mathrm{b}}$ Mimics a heavy meal in full contact with the tablet.

c Mimics a light meal partially contacted the tablet.

${ }^{d} p<0.05$.

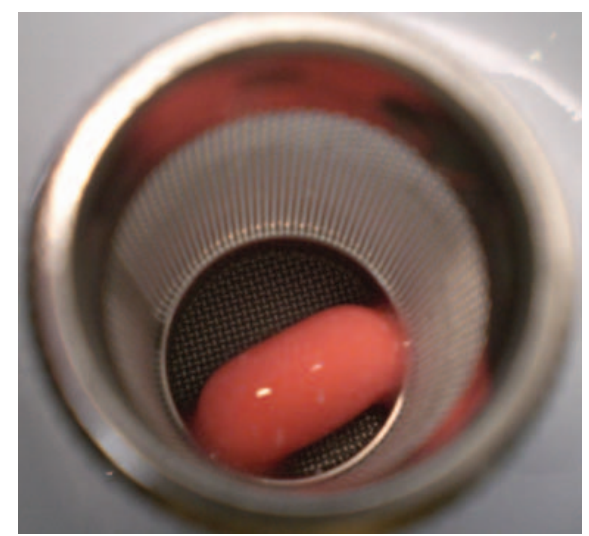

Figure 4. Polygel CR Tablet after being in an acidic medium for $2 \mathrm{~h}$.

disintegration apparatus would predict drug release in simulated fed state almost twice higher than using Apparatus 1, but the prediction of drug release in simulated fasted state using either apparatus is similar (Figure 3).

The disintegration of the CVS calcium supplement with vitamin D follows bulk disaggregation in a rapid pattern, which occurred in $3.71 \pm 0.25 \mathrm{~min}(n=5$, Table 5$)$. When the study was repeated placing a USP disk flat on the top of a tablet, its disintegration did not accelerate much, $2.86 \pm 0.12 \mathrm{~min}$ ( $n=5$, Table 5). The Nature Made calcium supplement with vitamin D was apparently manufactured by dry compression without a protective coat. The disintegration of this tablet was observed as erosion from the surface and was the slowest of the three brands (20.43 $\pm 0.93 \mathrm{~min}, n=9$, Table 5 ). Because of its longer disintegration time, placement of a USP disk flat on its top accelerated disintegration, which is probably caused by the bumping movements of the disk while the basket was raised and lowered inside the beaker $(9.88 \pm 0.68 \mathrm{~min}$, $n=9$, Table 5).

\section{CONCLUSIONS}

Medium change Method A (Add Directly) is recommended when conducting the dissolution of a Polygel CR tablet. The niacin release from such a tablet was biphasic: curved in acid stage and linear in buffer stage ( $\mathrm{pH}$ 6.8). There was no impact on drug release due to food weight and churning effect using USP dissolution Apparatus 1, while there may be an effect using USP disintegration apparatus with a disk. Disk adherence to a Polygel CR tablet affects medium buoyancy and leads to greater variation of drug release among samples in the simulated fed than in the simulated fasted study. The data from this simulation research also indicate that food weight does not accelerate disintegration remarkably in a tablet designed with rapid disintegration properties such as the calcium tablets studied. However, a meal in the stomach may speed up the disintegration of a slower disintegrating tablet.

\section{ACKNOWLEDGMENT}

The authors would like to thank Dr. Stephen Kerr and Dr. Dennis Wigandt at MCPHS-Boston for their scientific advice.

\section{REFERENCES}

1. Pernarowski, M.; Woo, W.; Searle, R. O. Continuous-flow apparatus for the determination of the dissolution characteristics of tablets and capsules. J. Pharm. Sci. 1968, 57 (8), 1419-1421.

2. Kramer, J.; Grady, L.T.; Gajendran, J. Historical Development of Dissolution Testing. In Pharmaceutical Dissolution Testing; Dressman, J. J, Kramer, J., Eds.; Taylor \& Francis Group: New York, 2005; $\mathrm{p} 8$.

3. Wong, G.; Collins, C.C. Dissolution Testing. In Preformulation in Solid Dosage Form Development; Adeyeye, M. C., Brittain, H. G., Eds.; Informa Healthcare USA Inc.: New York, 2008; pp 478-480.

4. Allen, L.V., Jr.; Popovich, N. G.; Ansel, H. C. Ansel's Pharmaceutical Dosage Forms and Drug Delivery Systems, 8th ed.; Lippincott Williams and Wilkins: Philadelphia, 2004, p 237.

5. O'Neil, M. J.; Smith, A.; Heckelman, P. E.; Budavari, S. The Merck Index, 13th ed.; John Wiley \& Sons, Inc.: Hoboken, NJ, 2001; pp 6552-6553.

6. Lemke, T. L.; Williams, D. A.; Roche, V. F.; Zito, S. W. Foye's Principles of Medicinal Chemistry, 6th ed.; Lippincott Williams \& Wilkins: Philadelphia, PA, 2008, p 1349. 
7. Marks, J.W. Niacin. MedicineNet, Inc. Web site. http:// www.medicinenet.com/niacin/article.htm (accessed Jan 15, 2009).

8. Tsang, G. The Myth of Calcium Supplements: Which One Is the Best?, 2004. HealthCastle Nutrition, Inc. Web site. http://www.healthcastle.com/calciumpill.shtml (accessed Jan 15, 2009).

9. Niacin Tablets. In United States Pharmacopeia and National Formulary USP 31-NF 26; The United States Pharmacopeial Convention, Inc.: Rockville, MD, 2008; pp 2799-2800.

10. Dissolution $<711>$. In United States Pharmacopeia and National Formulary USP 31-NF 26; The United States Pharmacopeial Convention, Inc.: Rockville, MD, 2008; pp 267-274.

11. Disintegration $<701>$. In United States Pharmacopeia and National Formulary USP 31-NF 26; The United States Pharmacopeial Convention, Inc.: Rockville, MD, 2008; pp 266-267.

12. Gibson, M. Pharmaceutical Preformulation and Formulation; Interpharm/CRC: Boca Raton, 2004; 108.

13. Washington, N.; Washington, C.; Wilson, C.G. Physiological Pharmaceutics; Taylor and Francis: New York, 2001; p 149.

14. Avdeef, A. Physicochemical profiling (solubility, permeability and charge state). Curr. Topics Med.Chem. 2001, 1 (4), 277-351.

15. Buffer Solutions. In United States Pharmacopeia and National Formulary USP 31-NF 26; The United States Pharmacopeial Convention, Inc.: Rockville, MD, 2008; pp 813-814.

16. Gray, V. A. Compendial Testing Equipment: Calibration, Qualification, and Sources of Error. In Pharmaceutical Dissolution Testing; Dressman, J., Krämer, J., Eds.; Taylor \& Francis Group, LLC: Boca Raton, FL, 2005; .p 43.

17. Klein, S.; Stippler E.; Wunderlich, M.; Dressman, J. Development of Dissolution Tests on the Basis of
Gastrointestinal Physiology. In Pharmaceutical Dissolution Testing; Dressman, J., Krämer, J., Eds.; Taylor \& Francis Group, LLC: Boca Raton, FL, 2005; 215.

18. Zar, J. H. Biostatistical Analysis, 4th ed.; Prentice Hall: Upper Saddle River, NJ, 1999; pp 80-81. 